\title{
COMPARATIVE RESULTS OF SELECTION IN THE EARLY AND LATE STAGES OF AN INBREEDING PROGRAMME
}

\author{
J. L. JINKS and H. S. POONI \\ Department of Genetics, University of Birmingham, Birmingham B15 2TT. U.K.
}

Received 23.vii.80

\begin{abstract}
SUMMARY
Selection for final height using three different selection criteria has been applied retrospectively to the records of two inbreeding experiments, using pedigree and single-seed-descent breeding programmes, carried out without selection within crosses of varieties 1 and 5 of Nicotiana rustica. In the pedigree programme the results of individual and family selection imposed at the $F_{3}, F_{4}$ and $F_{6}$ generations on the performance of the inbred families from the $F_{9}$ generation onwards are compared. In the single-seed-descent programme the results of individual selection in the $F_{2}$ are compared with those of delaying selection until the $F_{7} / F_{8}$ generations. The results show that selection is considerably more successful if it is delayed and that family selection is more successful than individual selection in the early generations.
\end{abstract}

\section{INTRODUCTION}

BEGINNING in 1946 (Mather and Vines, 1952) and again in 1967 (Perkins and Jinks 1973), two independent random samples of pure-breeding lines of Nicotiana rustica have been extracted from an initial cross between varieties 1 and 5 of the Birmingham collection.

The first sample was produced by the method of pedigree breeding, the second by single-seed-descent. The properties of the two samples of pure-breeding lines have been described in numerous publications (for example, Perkins and Jinks, 1968; Eaves and Brumpton, 1972; Perkins and Jinks, 1973; Jinks and Pooni, 1976) and they have been used to initiate a number of further breeding programmes (for example, Jinks et al., 1969; Virk and Jinks, 1977; Pooni et al., 1978; Pooni et al., 1980). They have, however, a value that has not been exploited as yet, namely, they allow us to examine, retrospectively, the consequences of any selection that might have been practised at any stage of the inbreeding programme. In this paper we have, therefore, compared the results of selection practised in the early and late generations.

\section{MATERial}

In the first sample, 20 randomly chosen $F_{2}$ plants of the cross of varieties 1 and 5 were self-pollinated to produce $20 \mathrm{~F}_{3}$ families. Two randomly chosen sibs from each $\mathrm{F}_{3}$ family of 20 plants were self-pollinated to produce $40 \mathrm{~F}_{4}$ families and two randomly chosen sibs from each $F_{4}$ family were self-pollinated to produce $80 \mathrm{~F}_{5}$ families. At this point each of the original $F_{2}$ plants was represented by four $F_{5}$ families. From the $F_{5}$ generation onwards the total number of families was kept constant at 80 , apart from 
random losses, by self-pollinating two sibs from only one of the two families that arose from sibs in the previous generation. A diagramatic representation of this pedigree taken from Breese (1954) is given by Towey and Jinks (1977).

In the second sample 100 randomly chosen $F_{2}$ plants were self-pollinated and two sibs raised from each of the resulting $100 \mathrm{~F}_{3}$ families. One randomly chosen sib, or occasionally the one surviving sib, of each family was self-pollinated to produce $100 \mathrm{~F}_{4}$ families. Again two sibs per family were raised and one chosen at random was self-pollinated to produce the $100 \mathrm{~F}_{5}$ families. By repeating this process 82 pure-breeding lines were obtained each traceable back to a different $F_{2}$ plant. Further details of the origin of these lines are given by Perkins and Jinks (1973).

The character we shall use for illustration is final height. This is the largest single component of the total phenotypic variation in material derived from the cross between varieties 1 and 5, it has one of the highest narrow heritabilities and repeatabilities over seasons and a relatively simple genetical control (Bucio Alanis, Perkins and Jinks, 1969; Eaves and Brumpton, 1972; Pooni, Jinks and Jayasekara, 1978).

\section{METHOD}

\section{(i) Pedigree data}

Although we have data on the pedigree inbreeding programme from the $F_{2}$ to the $F_{19}$ we shall assess the consequences of selection in three early generations, $F_{3}, F_{4}$ and $F_{6}$, on the performance of the resulting purebreeding lines. For the latter we shall use the means over the last nine occasions on which the inbred families were assessed.

The advantage of imposing selection retrospectively on a random sample of families is that we can subject them to a wide range of selection procedures and criteria. We shall use six combinations made up as follows:

1. Individual selection in which an individual plant in any generation is selected as parent on the basis of its own performance.

2. Family selection in which a family is selected on the basis of the average performance of all of its members and randomly chosen individuals of the selected families are used as parents.

Individual and Family selection will be used in combination with three selection criteria.

(a) Selection of the best 25 per cent individuals or families.

(b) Selection of those individuals or families which are superior to the means of contemporary samples of the better parent $\left(\mathbf{P}_{1}\right)$.

(c) Selection of those individuals or families which are superior to the means of contemporary samples of the heterotic $F_{1}$.

\section{(ii) Single-seed-descent data}

The emphasis in breeding by single-seed-descent is to go from the $F_{2}$ to a relatively inbred state e.g., $\mathrm{F}_{6}$ or $\mathrm{F}_{7}$ as rapidly as possible using any environmental treatment that will reduce generation time. There are, therefore, no field assessments under normal growing conditions between 
TABLE 1

Percentages of maximum achievable response to selection obtained by six different selection criteria in $F_{3}, F_{4}$ and $F_{6}$ generations

Generation of selection

\begin{tabular}{|c|c|c|c|c|}
\hline Type of selection & & $\mathrm{F}_{3}$ & $\mathrm{~F}_{4}$ & $F_{6}$ \\
\hline Top 25 per cent & $\begin{array}{l}\text { Individual } \\
\text { Family }\end{array}$ & $\begin{array}{l}11 \cdot 6 \\
74 \cdot 3\end{array}$ & $\begin{array}{l}40 \cdot 7 \\
64 \cdot 5\end{array}$ & $\begin{array}{l}88.9 \\
86.6\end{array}$ \\
\hline$>P_{1}$ mean & $\begin{array}{l}\text { Individual } \\
\text { Family }\end{array}$ & $\begin{array}{l}26 \cdot 4 \\
41 \cdot 2\end{array}$ & $\begin{array}{l}86 \cdot 4 \\
83 \cdot 5\end{array}$ & $\begin{array}{r}97 \cdot 2 \\
100.0\end{array}$ \\
\hline$>F_{1}$ mean & $\begin{array}{l}\text { Individual } \\
\text { Family }\end{array}$ & $\begin{array}{l}11 \cdot 7 \\
68 \cdot 8\end{array}$ & $\begin{array}{l}56.9 \\
56.9\end{array}$ & $\begin{array}{l}47 . \\
86 .\end{array}$ \\
\hline
\end{tabular}

the $F_{2}$ and some later generation such as the $F_{7}$ or $F_{8}$. In our experiment, the first field assessment after the $F_{2}$ was of 82 inbred families, 71 of which were $F_{8}$ 's and 11 were $F_{7}$ 's, the latter having been delayed by one generation because of an above average generation time.

\section{RESULTS}

\section{(i) Pedigree data}

The results of imposing the six types of selection at the $F_{3}, F_{4}$ and $F_{6}$ generations on the performance of the pure-breeding families $\left(F_{\infty}\right.$ families) derived from the selections are summarised in tables 1 and 2 . In table 1 the results are expressed as the percentage of the maximum achievable response to the particular type of selection. This maximum is the deviation of the

\section{TABLE 2}

Percentage selected and percentage success in choosing those $F_{3}, F_{4}$ and $F_{6}$ 's which produce the best pure-breeding lines using the six different selection criteria

Generation of selection

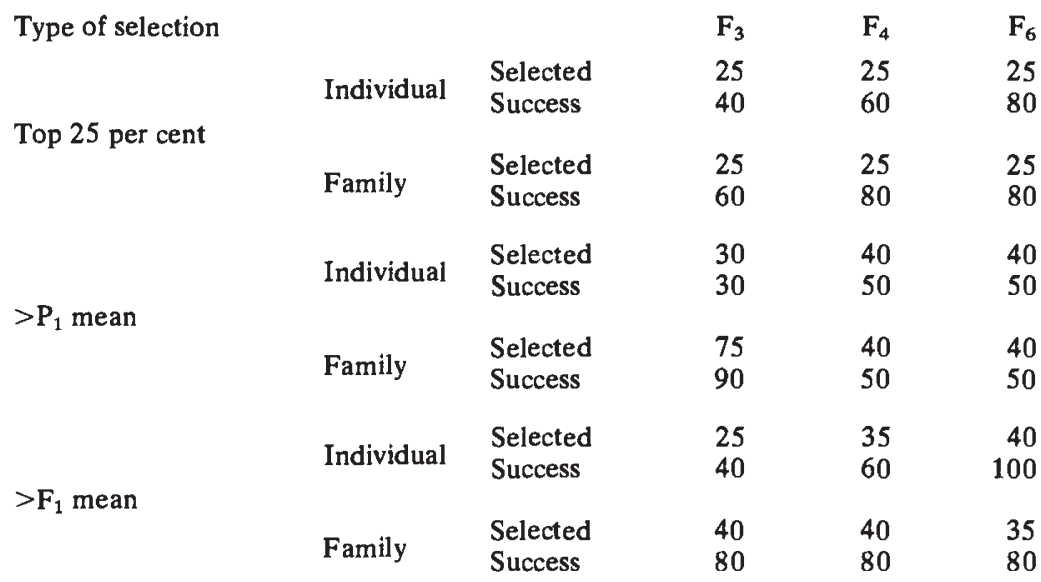


mean of the selected pure-breeding families $\left(\mathbf{S}_{\infty} \overline{\mathrm{F}}_{\infty}\right)$ from the mean of all pure-breeding families $\left(\overline{\mathbf{F}}_{\infty}\right)$ when the particular selection criterion is imposed on the population of $F_{\infty}$ families themselves. For example, if we select the top 25 per cent of $F_{3}$ individuals the mean of the pure-breeding lines derived from them $\left(S_{3 i} \overline{\mathrm{F}}_{\infty}\right)$ deviated from $\overrightarrow{\mathrm{F}}_{\infty}$ by 11.6 per cent of the deviation $S_{\infty} \overline{\mathrm{F}}_{\infty}-\overrightarrow{\mathrm{F}}_{\infty}$ when the top 25 per cent $\mathrm{F}_{\infty}$ families were selected; that is, $100\left(S_{3 i} \bar{F}_{\infty}-\bar{F}_{\infty}\right) /\left(S_{\infty} \bar{F}_{\infty}-\bar{F}_{\infty}\right)=11 \cdot 6$. The efficiency of selecting $F_{3}$ individuals on this criterion is, therefore, 11.6 per cent of that achieved by delaying selection until pure-breeding families have been obtained.

The same results are presented in table 2 in a way which attempts to show the probability of retaining or discarding those lineages which will produce the best $F_{\infty}$ families if selection is based on assessments made at $F_{3}, F_{4}$ and $F_{6}$. For each of the six selection criteria in each generation we have listed two percentages; the first is the percentage of individuals or families retained in each generation because they meet the selection criterion used; the second is the percentage of lineages retained after selection that will lead to $F_{\infty}$ families that would meet the same selection criterion if it were applied to the population of $F_{\infty}$ families. For example, when applying the top 25 per cent selection criterion to individuals in the $F_{3}$, the top 25 per cent of $F_{3}$ individuals were, of course, retained but only 40 per cent of the lineages that produced the top 25 per cent of $F_{\infty}$ families were retained in this selected sample, 60 per cent of the lineages that would have produced the best $F_{\infty}$ families were discarded including those that would have ranked 1,3 and 4 .

\section{(ii) Single-seed-descent}

Statistics summarising the properties of the pure-breeding lines produced by single-seed-descent from $F_{2}$ individuals selected on three criteria are given in table 3 . For example, where the selection criterion is the

\section{TABLE 3}

The percentage selected and percentage success in choosing those $F_{2}$ individuals which produce the best pure-breeding lines using the three different selection criteria and the percentage of the maximum achievable response to these selections

\begin{tabular}{|c|c|c|c|}
\hline & $\begin{array}{l}\text { Percentage } \\
\text { selected }\end{array}$ & $\begin{array}{c}\text { Percentage } \\
\text { success }\end{array}$ & $\begin{array}{l}\text { Percentage } \\
\text { response }\end{array}$ \\
\hline Top 25 per cent & 25 & 24 & $19 \cdot 9$ \\
\hline$>\mathrm{P}_{1}$ mean & 55 & 72 & $49 \cdot 0$ \\
\hline$>\mathrm{F}_{1}$ mean & 30 & 33 & $25 \cdot 0$ \\
\hline
\end{tabular}

top 25 per cent, the highest scoring 25 per cent of $F_{2}$ individuals were selected. The pure-breeding families produced from this selected sample by single-seed-descent included only 24 per cent of the highest scoring 25 per cent of pure-breeding families. The $F_{2}$ individuals that would have produced the remaining 76 per cent of the highest scoring pure-breeding families were, therefore, discarded because they did not meet the selection criterion imposed on the $F_{2}$. Because of this low rate of success the response to selection, measured as in table 1 , was only 19.9 per cent of that which 
could have been achieved by delaying selection until the pure-breeding families had been obtained. The summary statistics for the other two selection criteria were similarly obtained (table 3 ).

\section{(iii) Correlations between generations}

In table 4 are listed the correlations between the pairs of generations used in the investigation of the pedigree inbreeding programme. Two values

TABLE 4

\begin{tabular}{|c|c|c|c|c|}
\hline & $\mathrm{F}_{4}$ & $\mathrm{~F}_{6}$ & $F_{9}$ & $F_{\infty}$ \\
\hline $\mathrm{F}_{3}$ & $\begin{array}{l}0.65 \\
0.74\end{array}$ & $\begin{array}{l}0.54 \\
0.57\end{array}$ & $\begin{array}{l}0.14 \\
0.53\end{array}$ & $\begin{array}{l}0.18 \\
0.68\end{array}$ \\
\hline $\mathrm{F}_{4}$ & & $\begin{array}{l}0.45 \\
0.70\end{array}$ & $\begin{array}{l}0.45 \\
0.52\end{array}$ & $\begin{array}{l}0.68 \\
0.65\end{array}$ \\
\hline$F_{6}$ & & & $\begin{array}{l}0.70 \\
0.66\end{array}$ & $\begin{array}{l}0.72 \\
0.69\end{array}$ \\
\hline
\end{tabular}

are given for each pair; the upper value is the correlation between the individual plants chosen as parents and the means of the progeny families derived from them, the lower value is the correlation between the means of the family from which the individual parental plants were chosen and the means of the progeny families derived from them. They correspond to the data used for individual and family selection respectively. The purebreeding families resulting from the inbreeding programme are represented by two sets of data. Those correlations labelled $\mathrm{F}_{\infty}$ are, as previously, based upon the means of the pure-breeding lines over the last nine occasions on which they were assessed (section 3(i)). Since these means are known with considerably greater accuracy than the corresponding $F_{3}, F_{4}$ and $F_{6}$ family means an additional set of correlations based on the means of $F_{9}$ families raised on one occasion only are included for comparison.

For the inbred families produced by single-seed-descent, only one correlation can be obtained, namely that between $F_{2}$ individuals and the means of the $F_{8}\left(\right.$ or $\left.F_{7}\right)$ families derived from them. This has a value of $0 \cdot 32$.

\section{Conclusions}

To compare the selection responses produced by different selection strategies we have chosen a character, final plant height in the cross between varieties 1 and 5 of Nicotiana rustica, which is particularly favourable because of its high narrow heritability $(0 \cdot 6-0 \cdot 7)$, its simple and well established genetical control and its predictable response to environmental variation (including seasonal differences), in order to achieve results which are unambiguous. The results are therefore readily interpreted and convey a number of clear messages.

The first point that emerges from tables 1,2 and 3 is that by delaying selection until the $F_{4}$ or even the $F_{6}$ generation a population of inbred lines is 
produced which is superior in average performance and in composition to that produced by selection in either the $F_{2}$ or $F_{3}$ generations.

The second point that emerges from tables 1 and 2 is that on average family selection is superior to individual selection. But this superiority is conditional. It is most pronounced in the $F_{3}$ generation or when the selection intensity is high and it is least pronounced in the $\mathrm{F}_{6}$ generation or when the selection intensity is low.

The points that emerge from table 4 reinforce those already made. The six pairs of correlations between the $F_{3}, F_{4}$ and $F_{6}$ generations on the one hand and the $F_{9}$ and $F_{\infty}$ generations on the other summarise the relationships between the phenotypic variation upon which selection was practised and the realised additive genetic variation responsible for the heritable differences among the inbred lines to which they give rise. The ability of the selection in the $F_{3}, F_{4}$ and $F_{6}$ generations to influence the composition of the population of inbred families is clearly directly related to the magnitude of these correlations. And as already concluded from other comparisons (tables 1,2 and 3) this ability is lower in the $F_{3}$ than in the $F_{4}$ or $F_{6}$ and lower in individual than in family selection in $\mathrm{F}_{3}$ but not in the $\mathrm{F}_{6}$ generation. Two further points are worth noting. The relatively high heritability and repeatability are confirmed by the high parent/offspring mean correlations of the only two successive generations, $\mathrm{F}_{3}$ and $\mathrm{F}_{4}$, raised in different seasons.

The correlations involving $\mathrm{F}_{\infty}$ are consistently greater than those with $\mathrm{F}_{9}$, the essential difference being that the $F_{\infty}$, which are based on the means of nine independent field trials of the inbred lines will more accurately reflect the heritable by considerably reducing the nonheritable differences among them.

The conclusions of these retrospective selections are supported by actual selections for final height and environmental sensitivity within the cross of varieties 2 and 12 of $N$. rustica (Brumpton et al., 1977; Jinks et al., 1977). A comparison at the $\mathrm{F}_{7}$ generation of selections obtained by family selection starting in the $F_{3}$ and by single-seed-descent with selection delayed until the $\mathrm{F}_{7}$ showed the latter to be superior. But its superiority was greater for environmental sensitivity than for final height because of its lower heritability and repeatability over seasons.

\section{REFERENCES}

BREESE, E. L. 1954. Continuous variation in higher plants. Ph.D thesis, University of Birmingham.

BRUMPTON, R. J., BOUGHEY, H., AND JINKS, J. L. 1977. Joint selection for both extremes of mean performance and of sensitivity to a macro-environmental variable. I. Family selection. Heredity, 38, 219-226.

BUCIO ALANIS, L., PERKINS, J. M., AND JiNKS, J. L. 1969. Environmental and genotypeenvironmental components of variability. V. Segregating generations. Heredity, 24, $115-127$.

EAVES, L. J., AND BRUMPTON, R. J. 1972. Factors of covariation in Nicotiana rustica, Heredity, 29, $151-175$.

JINKS, J. L., JAYASEKARA, N. E. M., AND BOUGHEY, H. 1977. Joint selection for both extremes of mean performance and of sensitivity to a macro-environmental variable. II. Single seed descent. Heredity, 39, 345-355.

JINKS, J. L., PERKINS, J. M., AND BREESE, E. L. 1969. A general method of detecting additive, dominance and epistatic variation for metrical traits. II. Application to inbred lines. Heredity, 24, 45-57. 
JINKS, J. L., AND POONI, H, S, 1976. Predicting the properties of recombinant inbred lines derived by single seed descent. Heredity, 36, 253-266.

MATHER, K., AND VINES, A. 1952. The inheritance of height and flowering time in a cross of Nicotiana rustica. In Quantitative Inheritance, eds. E. C. Reeve and C. H. Waddington, pp. 49-80. H.M.S.O., London.

PERKINS, J, M., AND JINKS, J. L. 1968. Environmental and genotype-environmental components of variability. III. Multiple lines and crosses. Heredity, 23, 339-356.

PERKINS, J. M., AND JINKS, J, L. 1973. The assessment and specificity of environmental and genotype-environmental components of variability. Heredity, 30, 111-126.

POONI, H. S., JINKS, J, L., AND JAYASEKARA, N. E. M. 1978. An investigation of gene action and genotype $\times$ environment interaction in two crosses of Nicotiana rustica by triple test cross and inbred line analysis. Heredity, 42, 41-48.

POONI, H. S., JINKS, J. L., AND POONI, G. S. 1980. A general method for the detection and estimation of additive, dominance and epistatic variation for a metrical trait. IV. Triple test cross analysis for normal families and their selfs. Heredity, 44, 177-192.

TOWEY, P., AND JINKS, J. L. 1977. Alternative ways of estimating the number of genes in a polygenic system by genotype assay. Heredity, 39, 399-410.

VIRK, D. S., AND JINKS, J. L. 1977. The consequences of using inadequate testers in the simplified Triple Test Cross. Heredity, 38, 237-251. 